\title{
Dissociating advances in orthopaedic trauma management from the climbing patient expectations
}

\author{
Ali Lari ${ }^{1}\left[\right.$ Dohammad Alherz ${ }^{1} \cdot$ Ali Jarragh ${ }^{1}$
}

Received: 24 March 2021 / Accepted: 17 May 2021 / Published online: 24 May 2021

○) Springer-Verlag GmbH Germany, part of Springer Nature 2021

To the editor,

We read with interest the article by Keppler et al. [1] on the high post-surgical expectations in patients with complex tibial fractures. Their study highlights an important challenge, which in our view, emerges counterintuitively from the objective improvements in trauma management. The disarray and immediacy of trauma, historically at least, leave little to ponder beyond initial relief and salvage. Outcomes have therefore been naturally occupied with the bleakest of endpoints, such as mortality rates and amputations. With promising trends of up to $51 \%$ reductions in mortality after severe trauma in less than a decade [2], both patients and practitioners are now left with new-found room for prognostic manoeuvres and high expectations.

The resultant need for intermediate and long-term outcomes closer to the patients' previous baseline has justifiably turned to straightforward measures such as mobility, pain, scar appearance and time to fracture union, as these can be easily acquired, analysed and interpreted. While useful in assessing interventions, improvements on those fronts are arguably offset by the greater patient expectations accompanying advances in early trauma care [3]. Not uncommonly does the injured patient optimistically inquire into the eventuality of "returning to normal". As noted by the authors, unrealistic expectations may hinder an objectively reasonable outcome.

Indications of this can be seen in moving towards the opposite end of the spectrum, where in the most elective of cosmetic procedures, success is solely in the eyes of the patient. As such, we firstly deduce that in continuing along this trajectory, the objective outcome becomes secondary to the patient's perception of it. Secondly, we must learn to

Ali Lari

Dr.AliLari@gmail.com

1 Department of Orthopedic Surgery, Jaber Al-Ahmad AlSabah Hospital, Kuwait City, Kuwait disentangle the advances in care from the associated weight of greater expectations.

Perhaps key to this dilemma is the paradoxical observation that the the more severe the injury, the better the satisfaction rate [4]. A closer realization of the possibility of worst-case scenarios may minimize idealistic expectations and improve satisfaction with the end result. As such, future research in trauma may benefit from a greater focus on subjective measures of satisfaction, while developing preand post-operative communication approaches for managing patient expectations at the clinical level. Practitioners may be well served in not only exercising caution when it comes to making promises, but in actively reducing expectations especially in complex cases where outcomes unfold with long-term follow-up. To conclude in the stoic spirit: "Blessed is he who expects nothing, for he shall never be disappointed" (Alexander Pope).

\section{Declarations}

Conflict of interest The authors declare that they have no conflict of interest.

\section{References}

1. Keppler L, Keppler AM, Ihle C, Minzlaff P, Fürmetz J, Beck M, et al. Patients with complex proximal tibial fractures overestimate the prognosis of their injury. Eur J Trauma Emerg Surg. 2021. https://doi.org/10.1007/s00068-021-01644-w.

2. Glance LG, Osler TM, Mukamel DB, Dick AW (2012) Outcomes of adult trauma patients admitted to trauma centers in Pennsylvania, 2000-2009. Arch Surg 147(8):732-7. www.jamaarchivescme.com

3. Lateef F. Patient expectations and the paradigm shift of care in emergency medicine. J Emerg Trauma Shock. 2011;4:163-7 (Wolters Kluwer-Medknow Publications. PMC3132352).

4. Suk M, Daigl M, Buckley RE, Lorich DG, Helfet DL, Hanson B. Outcomes after orthopedic trauma: are we meeting patient expectations?-A prospective, multicenter cohort study in 203 patients. J Orthop Surg. 2017;25(1):230949901668408. https:// doi.org/10.1177/2309499016684089. 